\title{
Primary intracranial meningeal melanocytoma
}

\author{
Manoj Kumar ${ }^{1}$, Murat Gokden ${ }^{2}$ \\ 1. Division of Neuroradiology, University of Arkansas for Medical Sciences, United States. 2. Department of Pathology, \\ University of Arkansas for Medical Sciences, United States. \\ Correspondence: Manoj Kumar. Address: Division of Neuroradiology, UAMS, 4301 W. Markham Street, Little Rock, AR, \\ 72205, USA. Email: drmanojk93@gmail.com.
}

Received: October 16, 2012

DOI : $10.5430 /$ jbgc.v3n3p14

Accepted: November 27, 2012

Online Published: March 29, 2013

\section{Abstract}

Primary intracranial meningeal melanocytoma (PIMM) is an uncommon, neoplasm of the central nervous system. It is a relatively benign entity and needs to be considered in the differential diagnosis of pigmented, melanin containing intracranial lesions. A case of a 25 year old right handed male, who presented with right side facial numbness, tingling and headaches, is presented. MRI findings suggested a diagnosis of primary meningeal melanocytoma, which was surgically and pathologically confirmed.

\section{Key words}

Intracranial meningeal melanocytoma, MRI, Meckel’s cave

\section{I ntroduction}

There is a spectrum of primary melanotic lesions involving the central nervous system. It ranges from well differentiated primary melanocytomas at the benign end of the spectrum to the malignant melanomas at the other end ${ }^{[1]}$. Primary intracranial meningeal melanocytoma (PIMM) is a relatively rare lesion, which belongs to the benign end of these melanotic lesions. It has good prognosis, is histologically and clinically distinct from the malignant lesions, and needs to be considered in the differential diagnosis of melanotic lesions on imaging studies.

\section{Case report}

A 25 year old right handed male presented with one year history of right sided facial numbness and tingling, accompanied by headaches, with occasional periods of sharp right mid facial pain. The patient was on Pregabalin 150 mg twice a day and Carbamazepine $200 \mathrm{mg}$ daily. No other relevant drug history was present. On exam, the right corneal reflex was sluggish, the right masseter function was poor, decreased sensation in the right V2 distribution and hypalgesia in the right V1, V2 and V3 distribution were observed. The face was symmetric, normal palatal and tongue movements were observed and the extra-ocular muscles were unremarkable.

A MRI study of the brain was performed and it revealed a mass lesion in the right Meckels cave. The lesion was well defined and measured $2.0 \mathrm{~cm} \times 1.5 \mathrm{~cm}$, without any invasive or infiltrative characteristics. On the T2 weighted sequence, the lesion had a well defined hypointense rim, with mixed heterogeneous isointensities and hyperintensities (see Figure 1a 
and Figure 1b). It was predominantly hyperintense on the precontrast T1 weighted images, with mild heterogeneity (see Figure 2a and Figure 2b). The lesion showed gradient susceptibilities which could represent paramagnetic effects of melanin, hemorrhage or calcification. No significant post contrast enhancement was seen (see Figure 3a and Figure 3b).

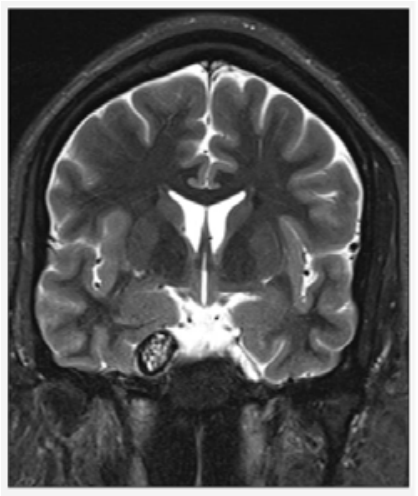

Figure 1a. T2 weighted coronal image shows heterogeneously hyperintense lesion involving the right meckel's cave with well defined hypointense rim.

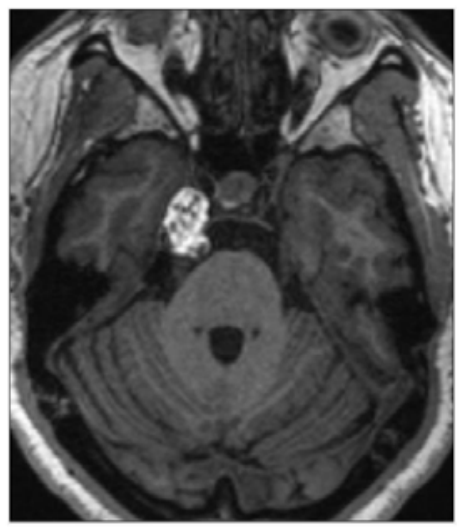

Figure 2a. Non contrast enhanced T1 weighted axial image shows a heterogeneously hyperintense lesion involving the right meckel's cave.

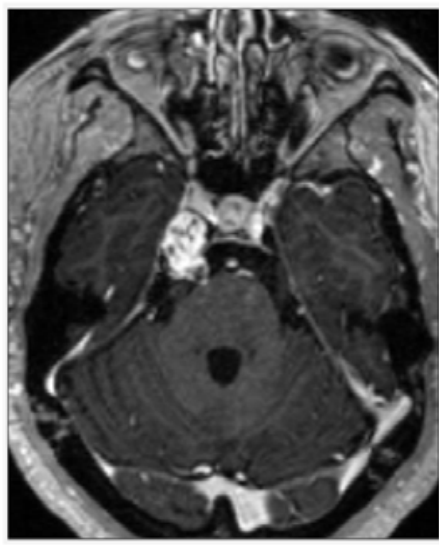

Figure 3a. Post contrast T1 weighted axial image shows no significant enhancement in the lesion involving the right meckel's cave.

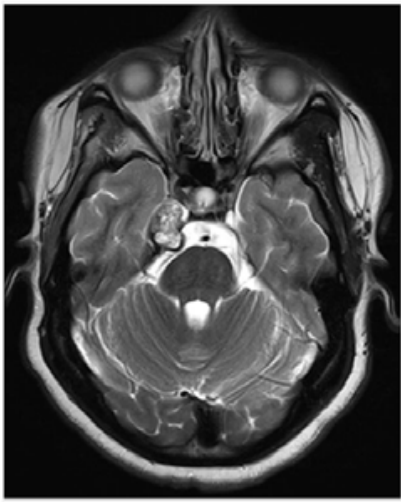

Figure 1b. T2 weighted axial image shows heterogeneously hyperintense lesion involving the right meckel's cave, with well defined hypointense rim.

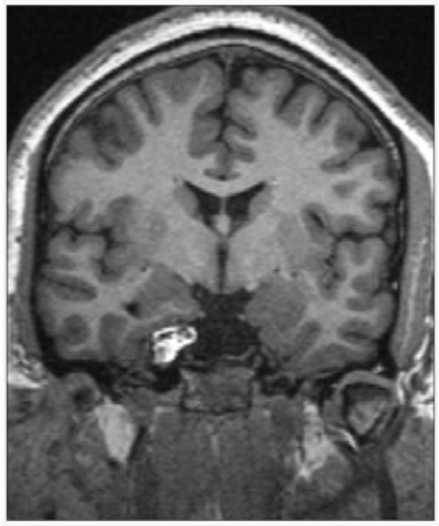

Figure 2b. Non contrast enhanced T1 weighted coronal image shows a heterogeneously hyperintense lesion involving the right meckel's cave.

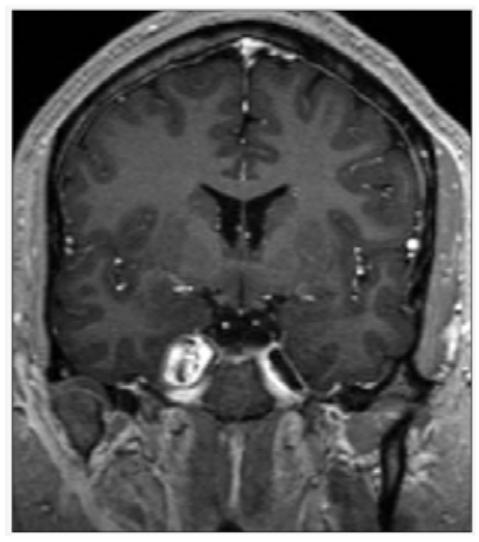

Figure 3b. Post contrast T1 weighted coronal image shows no significant enhancement in the lesion involving the right meckel's cave. 
A CT study was performed, which revealed an isodense, homogenous lesion in the right Meckel's cave, with no significant post contrast enhancement. No significant erosion, expansion, hyperostosis or permeative changes were seen involving the adjacent bone.

Based on the imaging findings, a differential diagnosis of primary meningeal melanocytoma, schwannoma with melanocytic features and meningioma with melanocytic features were suggested.

The lesion was surgically resected with a right middle fossa zygomatic approach. On resection the lesion was dark tan with soft tissue consistency. On pathology, the lesion showed marked pigmentation with intense melanin pigments. The cells within the lesion were epitheloid with uniform appearance, small nuclei and indistinct nucleoli (see Figure 4). No mitotic activity was observed. By immunohistochemical stains, the tumor cells were negative for EMA and positive for S100 and Mart1 (see Figure 5a, Figure 5b). Ki67 proliferative index was zero percent. A diagnosis of PIMM was made.

At one week follow up, the patient was symptomatically better and no new complaints were present.

\section{Discussion}

PIMM is a rare, slow growing tumor which arises from the normally present melanin cells in the leptomeninges of the central nervous system. PIMM's are primarily benign lesions, though relapse and malignant transition has been reported ${ }^{[2]}$. A few reports of leptomeningeal dissemination have been documented as well ${ }^{[3]}$. Our case presented with a right Meckel's cave lesion, with typical features of PIMM on the imaging studies.

Limas and Tio first described this entity, before which they were referred to as melanotic meningiomas ${ }^{[4]}$. The melanocytes are derived from the neural crest during early embryonic life and the distribution includes the spine, the posterior fossa and the supratentorium. In the brain the lesions are predominantly seen in the supratentorium and in the spine within the thoracic region ${ }^{[3]}$. Most of the reported PIMM's are in the posterior fossa and the Meckels cave is the second most common location ${ }^{[5-7]}$.

On CT study, these lesions are seen as iso to hyperdense on the noncontrast exam, are well defined, and extra-axial in location ${ }^{[8,9]}$. They may or may not show significant post contrast enhancement. Tumor calcification and hyperostosis of adjacent bone has rarely been described.

On MRI study, the appearance on T1 and T2 weighted sequences is dependent on the amount and distribution of the melanin pigment. The lesion reported by Litofsky et al. ${ }^{[10]}$ was homogenous and $\mathrm{T} 1$ isointense and $\mathrm{T} 2$ hyperintense, with little melanin pigment on pathology. In the studies of Naul et al. ${ }^{[8]}$ and Faro et al. ${ }^{[1]}$, the lesions were homogenously isointense on T1 weighted images and hypointense on T2 images and on pathology, the tumor cells contained scattered areas of cytoplasmic pigment deposition. Uematsu et al. ${ }^{[11]}$ reported high signal in the lesions on T1 and low signal on T2 weighted images and numerous melanin granules on the pathological specimen. Therefore it is plausible to conclude that the signal of the melanocytoma is strongly related to the amount of the melanin pigment present. The more melanin, the more T1 and T2 shortening occurs.

The biological and histological features, clinical presentation and progression of PIMM's differ considerably from the more aggressive meningeal melanomas. PIMM has a benign histology with lack of mitotic activity and necrosis. They are seen in tight nests with more pigmented cells at the periphery ${ }^{[12]}$. They have bland cytologic features with regular nuclei, distinct nuclear grooves, and no evidence of necrosis or invasion. These lesions are strongly immunoreactive for S-100 protein and HMB-45 and nonreactive for EMA. In contrast, the aggressive meningeal melanomas have varied histological and cytologic features, with sheets and loose nests of spindle, epitheloid and anaplastic cells. They have high cellularity, high nuclear to cytoplasmic ratios, increased mitosis, nuclear atypia, necrotic changes and invasive features. 
The differential diagnosis for PIMM would include an aneurysm, meningioma with melanocytic features (melanotic meningioma) and schwannoma with melanocytic features (melanotic schwannoma). Differential diagnosis for T2 hyperintense lesion in the cavernous and Meckel's cave region would also include cavernous angiomas. Other T1 hyperintense lesions would include primary malignant melanomas, metastases from melanoma and other hemorrhagic metastases. Dermoids and epidermoids are usually hyperintense on precontrast T1 weighted images.

Aneurysms show intense post contrast enhancement on CT and MRI studies. A whorled appearance with flow related artifacts may be seen on MRI studies ${ }^{[13]}$.

Cavernous angiomas are iso to hyperdense on noncontrast CT and iso to hyperintense on T2 weighted MRI study. They show marked homogenous post contrast enhancement on both the CT and MRI exams ${ }^{[14,15]}$.

Meningiomas are usually isointense on T1 and T2 weighted sequences, and show appreciable to intense post contrast enhancement ${ }^{[16]}$. Calcified meningiomas may show $\mathrm{T} 2$ and $\mathrm{T} 1$ hypointensities, but are seen as prominent hyperdense or calcific lesions on CT study. Occasionally melanocytes are trapped in a meningioma, but these cells do not represent a component of the tumor and are few in number ${ }^{[12]}$.

Melanotic schwannomas are usually seen as hyperdense lesions on CT study and may show calcifications within. On MRI imaging, these lesions are hypo to isointense on T1 weighted sequences, and iso to mildly hyperintense on T2 imaging. On post contrast imaging, varying patterns of enhancement are seen ${ }^{[17,18]}$. These lesions can contain melanin, fat and psammoma bodies and usually stain positive for S-100 protein and vimentin, with variable staining with HMB-45 and other melanocytic markers.

Primary malignant melanomas vary in radiological presentation, based on the amount of melanin and on presence or absence of hemorrhage ${ }^{[1]}$. They show T1 and T2 shortening and show variable enhancement. Presence of other lesions within the CNS and in the rest of the body needs to be ruled out before a diagnosis of this condition can be made. On pathology, the lesion shows high cellularity with pleomorphic cells, mitoses and prominent nucleoli, with abundant cytoplasm and dark pigmentation ${ }^{[17]}$.

Metastatic melanoma lesions usually are multiple ${ }^{[19]}$, located at the gray-white junction and show surrounding edema. They show variable hemorrhage, usually show enhancement, and resemble hemorrhagic metastases from breast, lung, choriocarcinoma, thyroid and renal cell cancer. Their radiological presentation varies, related to the amount of melanin and hemorrhage and size ${ }^{[20]}$.

Dermoids are seen as T1 hyperintense lesions similar to fat. They do not show significant post contrast enhancement or restricted diffusion and may demonstrate fat-fluid level ${ }^{[21]}$.

Epidermoids may appear iso to hyperintense on T1 weighted images ${ }^{[22,23]}$. They are hyperintense on the T2 weighted images and show restricted diffusion. On the post contrast images, they do not show significant enhancement. They are usually isodense or mildly hyperdense on CT studies ${ }^{[24]}$ and may show associated calcific components.

\section{Conclusion}

In summary, PIMM's are a distinct category of tumors, within the spectrum of melanin containing intracranial lesions. These are well differentiated lesions, histologically benign, and usually well treated by total surgical resection. They need to be considered and differentiated from other pigmented intracranial lesions. 


\section{References}

[1] Faro SH, Koenigsberg RA, Turtz AR, Croul SE. Melanocytoma of the cavernous sinus: CT and MR findings. AJNR. 1996; 17(6): 1087-1090. PMid:8791920

[2] Wang F, Qiao G, Lou X, Song X, Chen W. Malignant transformation of intracranial meningeal melanocytoma. Case report and review of the literature. Neuropathology. 2011; 31: 414-420. PMid:21062362 http://dx.doi.org/10.1111/j.1440-1789.2010.01160.x

[3] Grzesiuk AK, Serra ADR, Medeiros RTR. Meningeal Melanocytoma: an Unusual Presentation of a Rare Tumor. Rev Neurocienc. 2012; 20(1): 79-83.

[4] Limas C, Tio FO. Meningeal melanocytoma (“melanotic meningioma”): its melanocytic origin as revealed by electron microscopy. Cancer. 1972; 30(5): 1286-1294. http://dx.doi.org/10.1002/1097-0142(197211)30:5<1286::AID-CNCR2820300522>3.0.CO;2-V

[5] Turnbull M, Tom MI. Pigmented Meningioma. J Neurosurgery. 1963; 20: 76-80. PMid:14184988 http://dx.doi.org/10.3171/jns.1963.20.1.0076

[6] Botticelli AR, Villani M, Angiari P, Peserico L. Meningeal melanocytoma of Meckel’s cave associated with ipsilateral Ota’s nevus. Case report. Cancer. 1983; 51(12): 2304-2310. PMID: 6850510 http://dx.doi.org/10.1002/1097-0142(19830615)51:12<2304::AID-CNCR2820511223>3.0.CO;2-U

[7] Prabhu SS, Lynch PG, Keogh AJ, Parekh HC. Intracranial meningeal melanocytoma: a report of two cases and a review of the literature. Surg Neurol. 1993; 40(6): 516-521. PMID: 8235978 http://dx.doi.org/10.1016/0090-3019(93)90058-9

[8] Naul LG, Hise JH, Bauserman SC, Todd FD. CT and MR of meningeal melanocytoma. AJNR. 1991; 12(2): 315-316. PMid:1902034

[9] Chen CJ, Hsu YI, Ho YS, Hsu YH, Wang LJ, Wong YC. Intracranial meningeal melanocytoma: CT and MRI. Neuroradiology. 1997; 39(11): 811-814. PMid: 9406208 http://dx.doi.org/10.1007/s002340050510

[10] Litofsky NS, Zee CS, Breeze RE, Chandrasoma PT. Meningeal melanocytoma: diagnostic criteria for a rare lesion. Neurosurgery. 1992; 31(5): 945-948. PMid:1436422 http://dx.doi.org/10.1227/00006123-199211000-00019

[11] Uematsu Y, Yukawa S, Yokote H, Itakura T, Hayashi S, Komai N. Meningeal melanocytoma: magnetic resonance imaging characteristics and pathological features. Case report. J Neurosurgery. 1992; 76(4): 705-709. PMid:1545267 http://dx.doi.org/10.3171/jns.1992.76.4.0705

[12] Brat DJ, Giannini C, Scheithauer BW, Burger PC. Primary Melanocytic Neoplasms of the Central Nervous System. American Journal of Surgical Pathology. 1999; 23(7): 745-54. PMID:10403296 http://dx.doi.org/10.1097/00000478-199907000-00001

[13] Hacein-Bey L, Provenzale JM. Current Imaging Assessment and Treatment of Intracranial Aneurysms. AJR. 2011; 196: 32-44. PMid:21178044 http://dx.doi.org/10.2214/AJR.10.5329

[14] Namba S. Extracerebral cavernous hemangioma of the middle cranial fossa. Surg Neurol. 1983; 19(4): 379-388. PMID: 6836497 http://dx.doi.org/10.1016/0090-3019(83)90249-5

[15] Fehlings MG, Tucker WS. Cavernous hemangioma of the Meckel’s cave. Case report. J Neurosurg. 1988; 68(4):645-647. PMid:3351594 http://dx.doi.org/10.3171/jns.1988.68.4.0645

[16] Buetow MP, Buetow PC, Smirniotopoulos JG. Typical, Atypical and Misleading features in Meningioma. Radiographics. 1991; 11: 1087-1106. PMid:1749851

[17] Smith AB, Rushing EJ, Smirniotopoulos JG. Pigmented lesions of the central nervous system: radiologic-pathologic correlation. Radiographics. 2009; 29(5): 1503-24. PMID: 19755608 http://dx.doi.org/10.1148/rg.295095109

[18] Bendszus M, Urbach H, Wolf HK, Schramm J, Solymosi L. Magnetic resonance imaging of the intraspinal Melanotic schwannoma. Eur Radiology. 1988; 8(7): 1197. PMID: 9724438 http://dx.doi.org/10.1007/s003300050534

[19] King DM. Imaging of Metastatic Melanoma. J HK Coll Radiol. 2004: 7: 66-69.

[20] Escott EJ. A Variety of Appearances of Malignant Melanoma in the head: A Review. Radiographics. 2001; 21: 625-639. PMid:11353111

[21] Brown JY, Morokoff AP, Mitchell PJ, Gonzales MF. Unusual MRI Imaging Appearance of an Unusual Intracranial Dermoid cyst. AJNR. 2001; 22: 1970-72. PMid:11733334

[22] El-Kalliny M, Van Loveren H, Keller JT, Tew JM. Tumors of the lateral wall of the cavernous sinus. J Neurosurg. 1992; 77: 508-14. PMid:1527607 http://dx.doi.org/10.3171/jns.1992.77.4.0508

[23] Horowitz BL, Chari MH, James R, Bryan RN. MR of intracranial epidermoid tumor: correlation of in vivo imaging with in vitro spectroscopy. AJNR. 1990: 11: 299-302. PMid:2107713

[24] Latack JT, Kartush JM, Kernink JL, et al. Epidermoidomas of the cerebellopontine angle and temporal bone: CT and MRI aspects. Radiology. 1985: 157: 361-366. PMid:3876574 